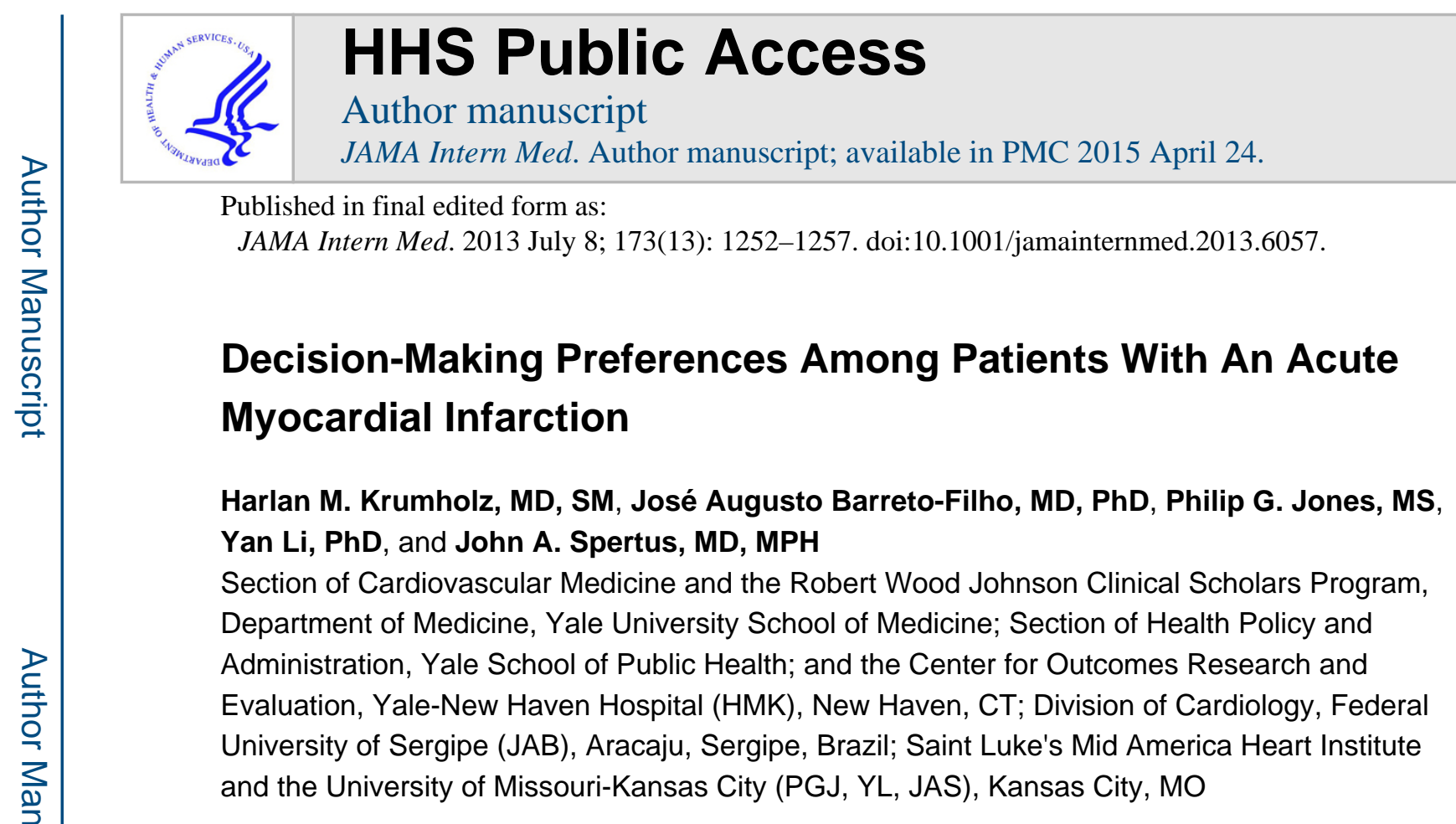

\title{
TO THE EDITOR
}

Despite numerous calls for greater participation by patients in the medical decision-making process, ${ }^{1,2}$ shared decision-making is not yet integrated into routine medical care, perhaps because of a perception that patients wish to defer to their physicians. We sought to investigate preferences for participation in the decision-making process among individuals hospitalized with an acute myocardial infarction (AMI).

\section{METHODS}

We combined data from 2 similar AMI registries: Translational Research Investigating Underlying Disparities in Acute Myocardial Infarction Patients' Health Status (TRIUMPH)

\footnotetext{
Correspondence: Dr. Krumholz, 1 Church Street, Suite 200, New Haven, CT 06510 203-764-5885; (f) 203-764-5653;

harlan.krumholz@yale.edu.

Dr. Barreto-Filho was affiliated with the Center for Outcomes Research and Evaluation at Yale-New Haven Hospital during the time that the work was conducted.

Author Contributions:

Study concept and design: Krumholz, Spertus

Acquisition of data: Krumholz, Spertus

Analysis and interpretation of data: Barreto-Filho, Jones, Krumholz, Li, Spertus

Drafting of the manuscript: Krumholz

Critical revision of the manuscript for important intellectual content: Barreto-Filho, Jones, Krumholz, Li, Spertus

Statistical analysis: Jones, $\mathrm{Li}$

Obtained funding: Krumholz, Spertus

Administrative, technical, or material support: N/A

Study supervision: Krumholz, Spertus

Conflict of Interest Disclosure:

Dr. Krumholz chairs a cardiac scientific advisory board for UnitedHealth and is the recipient of a research grant, through Yale University, from Medtronic. Dr. Spertus has received grant support from Lilly, Genentech, and EvaHeart. He serves on a cardiac scientific advisory board for UnitedHealth, and as a consultant to Genentech, Amgen, and St. Jude Medical. He has an equity position in Health Outcomes Sciences and owns the copyright to the Seattle Angina Questionnaire, Kansas City Cardiomyopathy Questionnaire, and Peripheral Artery Questionnaire.

Data Access and Responsibility:

Mr. Jones and Dr. Li had full access to all the data in the study and take responsibility for the integrity of the data and the accuracy of the data analysis.
} 
and the Prospective Registry Evaluating Outcomes After Myocardial Infarctions: Events and Recovery (PREMIER). The studies, which have been previously described, had similar inclusion criteria and common enrollment sites. ${ }^{3,4} \mathrm{We}$ collected, among other information, detailed data on clinical comorbidities, admission and discharge medications, presenting electrocardiogram, and treatments during the first 24 hours through chart abstraction. Trained hospital research staff administered interviews between 24 and 72 hours after admission.

We assessed patient shared decision-making preferences with the question, Given the information about risks and benefits of the possible treatments, who should decide which treatment option should be selected? ${ }^{5}$ The response rate to the question was $96.6 \%(2,414$ of 2,498$)$ for PREMIER and $97.3 \%(4,222$ of 4,340) for TRIUMPH. Patients responded on a 5 -point Likert scale: $1=$ doctor alone, $2=$ mostly doctor, $3=$ doctor and you, $4=$ mostly you, $5=$ you alone. We dichotomized the response into 2 categories: passive (Likert scores 1 and 2 ) and active (3, 4, and 5). We compared the baseline characteristics of patients with and without a preference to be actively involved and developed a predictive model employing a hierarchical modified Poisson regression model, which adjusted for clustering at the hospital level. All tests for significance were 2-tailed with an a level of 0.05, and were conducted with SAS version 9.1.3 (SAS Institute Inc., Cary, NC) and R version 2.6.0 (Vienna, Austria).

\section{RESULTS}

Of 6,636 patients in the study sample, 4,536 (68\%) desired active engagement in shared decision-making (Table). Among those, 2,735 (60.3\%) indicated that the doctor and patient should participate equally, $696(15.3 \%)$ indicated that the patient should predominantly determine the decision, and 1,105 (24.4\%) said that the patient alone should determine it. For all patient characteristics, the majority (68\%) preferred an active role in decisionmaking. Those who preferred an active role tended to be younger, but none of the age groups had less than a majority that preferred active engagement. Compared with patients who did not complete high school, patients who had a college degree and those with a graduate degree had a much greater likelihood of preferring an active approach. However, even among those with less than a high school education, 58\% preferred an active style. Financial resources were not associated with preferences. In the multivariable model, we identified 7 variables with a significant and independent association with an active decisionmaking preference: women, white race, higher education, smoker, heart failure, lower GRACE risk score, and not undergoing PCI during the hospitalization. The discrimination of the final model was modest, with a c-statistic of 0.61 .

\section{COMMENT}

More than two-thirds of AMI patients indicated a preference to play an active role in the decision-making process, and of those, about a quarter preferred that the decision be theirs alone, rather than shared with their doctor. In addition, demographic and clinical characteristics did not predict well who preferred an active role. The results of this study 
highlight that a great majority of patients want to be involved in decision-making, while also showing that there is a marked minority of patients who would prefer to be passive.

While some studies used hypothetical situations to assess decision-making preferences, we directly elicited patients' preferences at the time that decisions were being made. The predictive model had limited discrimination. Our findings indicate that physicians who aspire to provide patient-centered care should assess patients' decision-making preferences by directly asking each patient.

A potential limitation of this study is the approach we used to elicit patient decision-making responses. We may have failed to capture the full scope of patient preferences, and mixedmethods studies may reveal nuances to these preferences that are not readily apparent in a fixed-response question.

Decision-making preferences vary among patients after an AMI, but many patients prefer an active style. To know a patient's preference requires a specific conversation. Our challenge now is to develop systems that fully respect these preferences and ensure that patients who prefer an active role are given that opportunity.

\title{
ACKNOWLEDGMENT
}

We gratefully acknowledge Vishnu Patlolla, Gregory Mulvey, and Marian Mocanu for their contributions, which were provided without compensation.

\begin{abstract}
Sources of Funding: The TRIUMPH study was supported by grant P50 HL077113 from the Specialized Center of Clinically Oriented Research in Cardiac Dysfunction and Disease from the National Heart, Lung, and Blood Institute in Bethesda, Maryland. PREMIER was funded by CV Therapeutics, Inc., Palo Alto, California. This study was also funded in part by CV Outcomes, Inc., Kansas City, Missouri. During the time that this work was conducted, Dr. Barreto-Filho was a postdoctoral fellow at Yale University supported by grant 3436-10-1 from CAPES (Coordenação de Aperfeicoamento de Pessoal de Nível Superior, Ministry of Education, Brazil). Dr. Spertus has been funded by the National Heart, Lung, and Blood Institute in Bethesda, Maryland, the American Heart Association in Dallas, Texas, and the American College of Cardiology Foundation in Washington, District of Columbia. Dr. Krumholz is funded by grant U01 HL105270-03 (Center for Cardiovascular Outcomes Research at Yale University) from the National Heart, Lung, and Blood Institute in Bethesda, Maryland.
\end{abstract}

Role of the Sponsors: The funding sponsors had no role in the design and conduct of the study; in the collection, management, analysis, and interpretation of the data; or in the preparation, review, or approval of the manuscript.

\section{References}

1. Allen LA, Stevenson LW, Grady KL, et al. Decision making in advanced heart failure: a scientific statement from the American Heart Association. Circulation. 2012; 125(15):1928-1952. [PubMed: 22392529]

2. Walsh MN, Bove AA, Cross RR, et al. ACCF 2012 health policy statement on patient-centered care in cardiovascular medicine: a report of the American College of Cardiology Foundation Clinical Quality Committee. J Am Coll Cardiol. 2012; 59(23):2125-2143. [PubMed: 22591882]

3. Arnold SV, Chan PS, Jones PG, et al. Translational Research Investigating Underlying Disparities in Acute Myocardial Infarction Patients' Health Status (TRIUMPH): design and rationale of a prospective multicenter registry. Circ Cardiovasc Qual Outcomes. 2011; 4(4):467-476. [PubMed: 21772003]

4. Spertus JA, Peterson E, Rumsfeld JS, Jones PG, Decker C, Krumholz H. The Prospective Registry Evaluating Myocardial Infarction: Events and Recovery (PREMIER)--evaluating the impact of myocardial infarction on patient outcomes. Am Heart J. 2006; 151(3):589-597. [PubMed: 16504619] 
5. Deber RB, Kraetschmer N, Irvine J. What role do patients wish to play in treatment decision making? Arch Intern Med. 1996; 156(13):1414-1420. [PubMed: 8678709] 

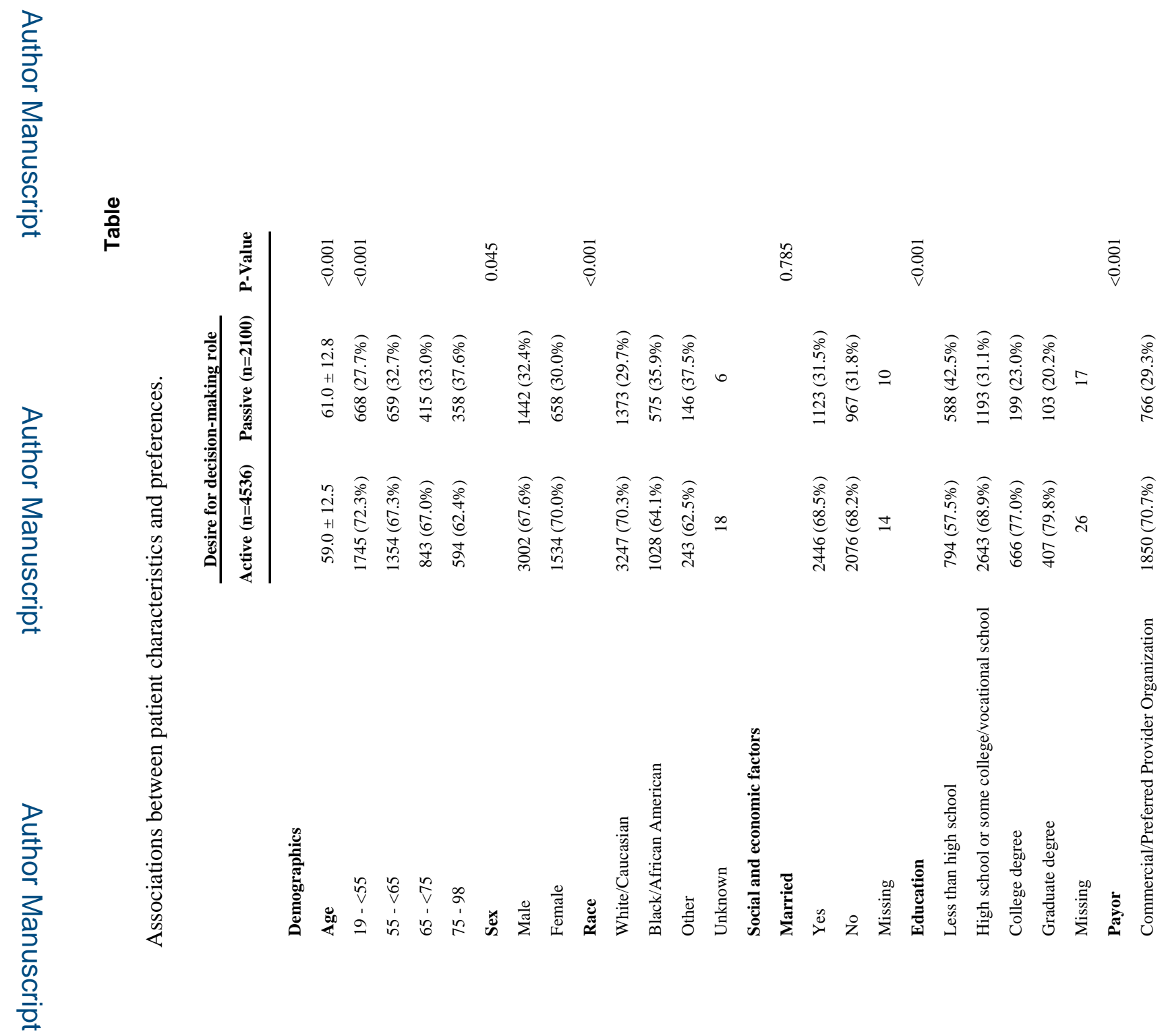

JAMA Intern Med. Author manuscript; available in PMC 2015 April 24. 


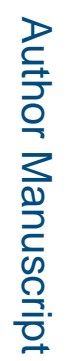

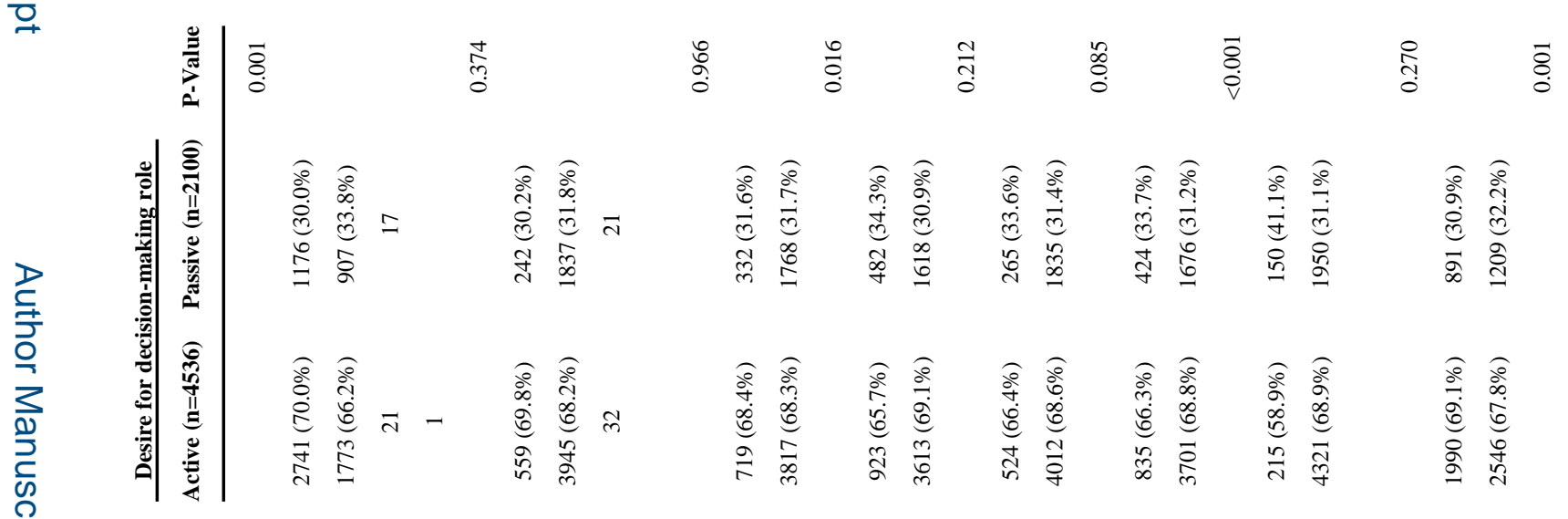

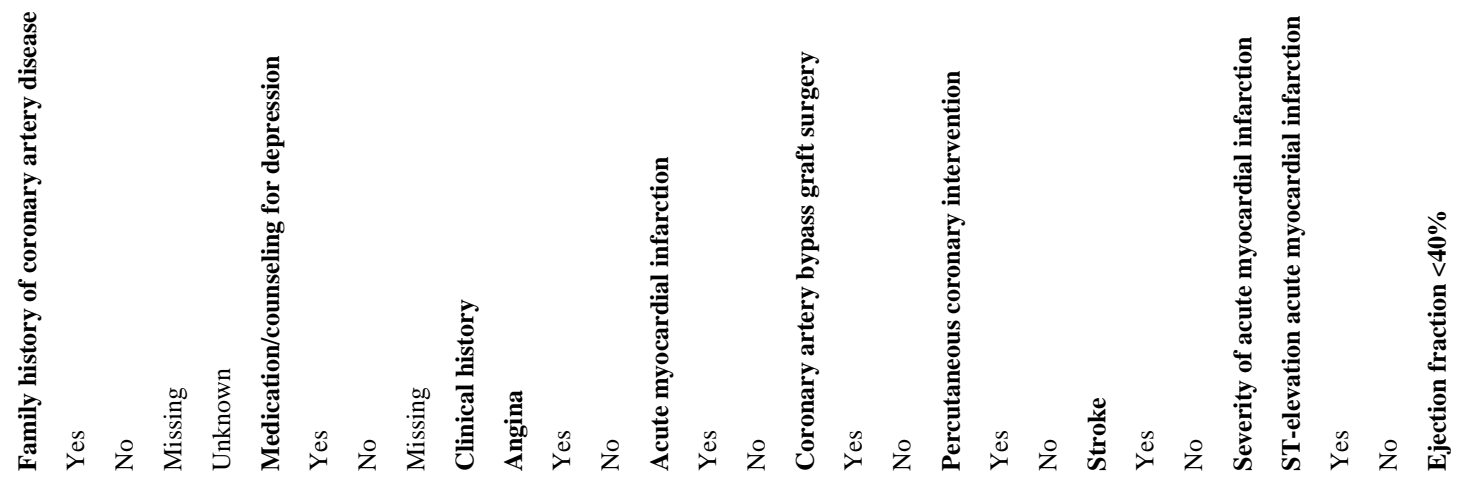


Krumholz et al.

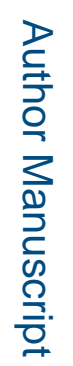

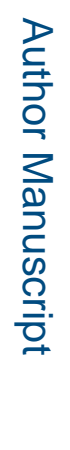

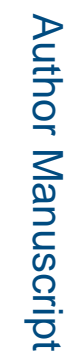

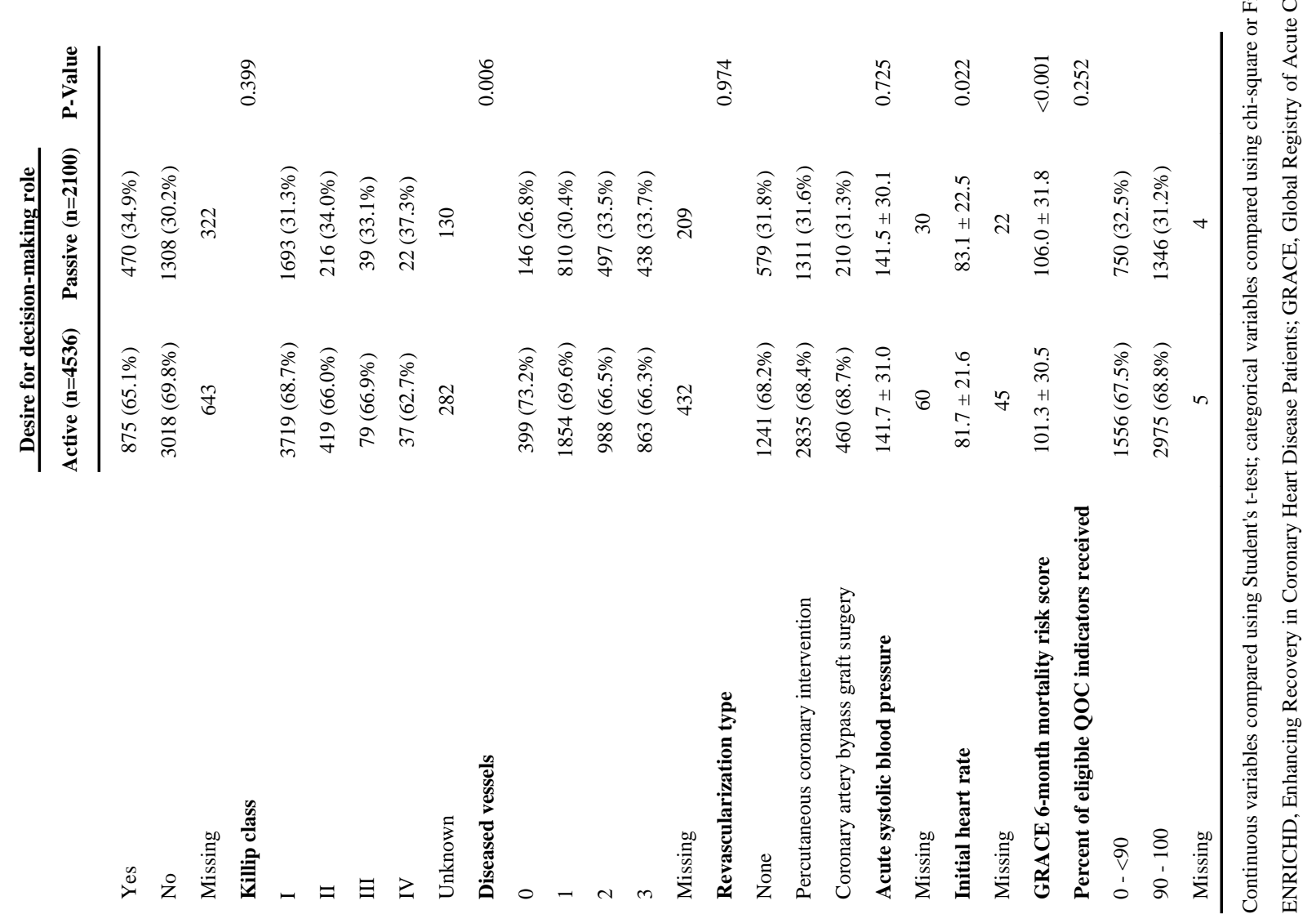

JAMA Intern Med. Author manuscript; available in PMC 2015 April 24. 